\title{
PSICOLOGIA E DESIGUALDADE SOCIAL
}

\section{Ana Mercês Bahia Bock}

Autora para correspondência: Ana Mercês Bahia Bock - anabbock@gmail.com

Psicóloga. Doutora em Psicologia Social. Professora titular na Pontifícia Universidade Católica de São Paulo, PUC/SP, Brasil

\section{R E S U M O}

O texto debate a desigualdade social como a grande questão brasileira. Os índices comprovam que o Brasil é uma das nações mais bem classificadas na produção de riquezas, mas a distribuição destas o coloca entre as nações campeãs de desigualdade social. Apesar da forte presença deste aspecto, a Psicologia tem desvalorizado ou ignorado a desigualdade social como um aspecto determinante da constituição das subjetividades. $\bigcirc$ artigo argumenta que esta falta de prioridade ao assunto é uma questão epistemológica que deve ser enfrentada e superada (transformada) na Psicologia. Esta superação se dará pela adoção de uma visão de sujeito e de sua relação com o mundo que adota como categoria fundamental a historicidade, afirmando a subjetividade como aspecto da realidade que se constitui como uma dimensão do real. Subjetividade e objetividade são uma relação dialética de constituição mutua. Ignorar esta relação leva e tem levado à psicologia a se constituir como ideologia que oculta a produção social da desigualdade.

Palavras chaves: desigualdade social; dimensão subjetiva; subjetividade 
This text discusses the social inequality as the great Brazilian issue. The statistics show that Brazil is one of the topranked nations in wealth production, but the distribution places it among the social inequality champions. Despite the strong presence of this aspect, psychology has devalued or ignored social inequality as a key aspect of the constitution of subjectivities. The article argues that this lack of subject-priority is an epistemological matter that must be faced and overcome (transformed) in Psychology. This will be overcome by adopting a vision of subject and his relationship to the world that adopts the historicity as elementary category, asserting subjectivity as an aspect of reality that is as a dimension of the real. Subjectivity and objectivity are a dialectical relationship of mutual constitution. Ignoring this relationship leads and has led to psychology to be an ideology that hides the social production of inequality.

Keywords: social inequality; subjective dimension ; subjectivity 
A tese defendida neste artigo é a de que a desigualdade social, maior problema vivido pelo Brasil, é ignorada pela psicologia e isto torna o discurso desta ciência ideológico.

Assim, vamos primeiro apresentar a desigualdade como o maior problema brasileiro; em seguida, dizer da desvalorização deste problema pela psicologia, buscando suas razões epistemológicas e apresentando a tese de que a psicologia tem se tornado um discurso ideológico, na medida em que não toma a realidade social da desigualdade como uma questão central para pensar a subjetividade. Por fim, defender a importância deste tema e dizer de sua relação com a constituição da subjetividade. Scalon, ao prefaciar o livro de Marcelo Medeiros afirma em suas primeiras linhas que "Se existe algum consenso entre sociólogos e economistas brasileiros, é o de que a desigualdade é uma questão central em nosso país"'.

A história brasileira, em seus mais de 300 anos de escravidão, é marcada pela presença de uma elite política e econômica que sempre privilegiou seus interesses em detrimento das necessidades da maioria da população. Os momentos atuais da história brasileira estão ainda carregados de exemplos e eventos que, sem pudor, são exemplos deste modo político de nosso país.

Ao refletir sobre o termo desigualdade, afirma que este implica obrigatoriamente em uma relação com um padrão de justiça distributiva; "[...] igualdade e desigualdade social pressupõem referência a uma unidade, a uma identidade coletiva ou a um todo no interior do qual ganham sentido julgamentos morais sobre critérios e padrões distributivos"2. Da mesma forma indica a necessidade de trazermos para - debate a resposta à pergunta: desigualdade de quê? ${ }^{3}$. E sem a pretensão de fazer aqui estes debates, afirmamos dois aspectos importantes para nossa finalidade: primeiro é que o padrão de desigualdade/ igualdade social é construído histórica e culturalmente em uma dada sociedade. Ou seja, no debate, na mensuração ou na teorização sobre desigualdade social há pressuposta uma filosofia de justiça ${ }^{2,3}$. Em segundo, a desigualdade social faz referência a distribuição da riqueza e às condições desiguais de acesso e bem-estar. Falamos, portanto, de um país que é caracterizado por uma população que tem acesso desigual à riqueza produzida coletivamente e usufrui de condições de vida também desiguais.

O índice de GINI, no Brasil, em 2014 estava em $0,490^{4}$. O Relatório sobre a distribuição de renda e da riqueza da população brasileira, sob a responsabilidade do Ministério da Fazenda, publicado em 2016, sobre dados de declarações de renda (IRPF) de 2014, realizadas em 2015 pelos contribuintes, indica que a desigualdade no Brasil é bastante grande. Na análise apresentada pelo relatório, a população é dividida em grupos de $10 \%$, os chamados decis. A parcela dos $10 \%$ mais ricos é subdivida em faixas de $5 \%, 1 \%$ e $0,1 \%$, como é feito nos países mais ricos. Os números de 2014:

[...] mostram que o $0,1 \%$ mais rico da população brasileira, ou 27 mil pessoas num universo de 27 milhões de declarantes do IRPF, afirmaram possuir $\mathrm{R} \$ 44,4$ bilhões em rendimento bruto tributável e R 159,7 bilhões em rendimento total bruto. Eles possuem $6 \%$ da renda bruta e $6 \%$ dos bens e direitos líquidos do país. Essa parcela mais abastada também aufere uma renda $3.101 \%$ superior ao rendimento médio dos declarantes de IRPF e possuem uma quantidade de bens e direitos $6.448 \%$ superior à média. Já os $5 \%$ mais ricos possuem $28 \%$ da renda bruta e $28 \%$ dos bens e direitos ${ }^{4}$.

A divisão em milésimos dentro do centil mais rico também possibilita a comparação entre os ricos e produz informações que retratam $\circ$ tamanho da desigualdade no Brasil. Os números mostram que ○ $0,1 \%$ da população mais rica concentra $44,3 \%$ do rendimento bruto do $1 \%$ mais rico. "Em outras palavras, no grupo do $1 \%$ de pessoas mais ricas do país, apenas um décimo delas possui quase a metade da renda"4.

Poderíamos ainda ampliar as informações com os dados sobre as desigualdades que têm a característica étnico-racial como seu crivo; ou ainda aquelas que marcam as diferentes regiões do país; ou ainda de gênero. Poderíamos trazer dados que falam das condições de vida e bem-estar. $O$ que se sabe é que todos os dados e informações permitem a mesma conclusão: a desigualdade no país é bastante profunda e permanente.

As abordagens mais complexas da desigualdade, tanto no campo da sociologia como da economia, já apresentam aspectos, com certeza de maior dificuldade para sua mensuração, mas que 
inegavelmente fazem parte do fenômeno: são os aspectos afetivos e valorativos.

Souza ${ }^{5,6}$ nos apresenta sua reflexão, neste campo, defendendo para que se considere os aspectos simbólicos envolvidos no fenômeno da reprodução cotidiana da desigualdade social no Brasili5,6. A internalização de uma hierarquia social garante significações de superioridade e inferioridade nas diversas esferas da sociedade. A estrutura de relações que acompanha e marca o fenômeno da desigualdade social é caracterizada por redes invisiveis e objetivas que qualificam e desqualificam indivíduos e grupos, distinguindo-os. Souza chama - grupo desvalorizado de "ralé"6,7, marcando com este forte termo um grupo social que tem acesso a pequena parte da riqueza, vive sob condições precárias e é desvalorizado na hierarquia social.

Estes argumentos e dados apresentados buscam indicar que a desigualdade social é, com certeza, o maior problema e a marca estrutural da sociedade brasileira. As relações sociais ocorrem neste cenário de desigualdade; a constituição de identidades e de subjetividades também; os comportamentos, os desejos, os projetos, os valores e as significações, tudo se passa neste contexto. Mas a Psicologia ignorou este fato e pensou os sujeitos sem considerar a desigualdade social.

Poderíamos empreender um estudo que pudesse nos trazer dados sobre a ausência da desigualdade na psicologia. No entanto, parece bastar afirmar que a terminologia da BVS-PSI não contempla este termo. Se ainda quisermos completar esta busca superficial, podemos tomar os Anais do XVIII Encontro Nacional da ABRAPSO - Associação Brasileira de Psicologia Social $(2015)^{A}$, onde o termo desigualdade social não é frequente. Apenas três trabalhos possuem, no título, a palavra desigualdade (sendo 2 deles do nosso grupo na PUCSP); 12 trabalhos trazem a palavra desigualdade social (4 deles são nossos) e na maioria a desigualdade não é objeto de estudo e sim apenas citação da condição dos sujeitos pesquisados. Dos grupos de trabalho do mesmo Encontro da ABRAPSO, apenas dois possuem título indicando a ênfase na desigualdade social ${ }^{B}$.
Por que a Psicologia ignorou a desigualdade social? Esta talvez seja a questão mais importante de ser abordada por nós. Quais os aspectos da psicologia que a levariam a estar de costas para a realidade social tão gritante quanto a da desigualdade social. Nossa tese é de que a questão é epistemológica, ou seja, localiza-se na concepção de sujeito na qual a psicologia se baseou.

Temos considerado o ano de 1875 como $\circ$ marco para falarmos em Psicologia como área da ciência. As condições de sua construção estão, portanto, no século XIX, quando a burguesia ascende ao poder e as condições históricas e os interesses desta classe ascendente vão permitir o desenvolvimento do que chamamos de ciência moderna. Ênfase na razão humana, no indivíduo, na liberdade, na possibilidade e interesse na transformação do mundo, tanto material quanto social, vão permitir o surgimento de um conhecimento racional que ultrapassa o senso comum, tão enviesado pela interferência dos afetos, opiniões, crenças e valores dos indivíduos. O método científico que marcou a ciência moderna permitiu aos cientistas observar o real de modo objetivo. Nasce uma ciência racional, empírica, positivista, experimental, quantitativa e determinista.

Mas sua principal característica, para efeitos desta reflexão, é o fato de ser dicotômica em sua epistemologia. $O$ esforço racional para garantir um saber objetivo sobre a realidade, incluída a subjetividade, foi separar estes dois âmbitos: subjetividade e objetividade, que "passam a ser vistos como autônomos, com movimento próprio e natural. Caberia à Psicologia estabelecer, da melhor maneira possível, os mecanismos de interação entre os aspectos subjetivos e os aspectos objetivo"8.

Mas, hoje, podemos dizer que tanto nas visões que privilegiaram a objetividade, quanto nas que privilegiaram a subjetividade, ocorreu a separação entre estes âmbitos como visões de que se relacionariam como mútua influência. Tanto a objetividade quanto a subjetividade forma naturalizadas por este processo de pensamento, ou seja, as razões para compreender seu funcionamento, desenvolvimento ou movimento estariam dadas no

A Anais do XVIII Encontro Nacional da ABRAPSO acessado no site da entidade em 04/09/2016: file:///C:/Users/ana/OneDrive/Documentos/XVIII_ENABRAPSO_2015\%20 (1).pdf

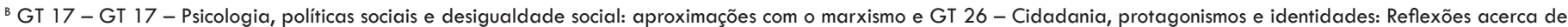
itinerários de enfrentamento das desigualdades sociais e outras frentes de emancipação humana. 
próprio objeto- no indivíduo.

A realidade social, a sociedade, as condições de vida e a desigualdade social ficaram do lado de fora das explicações e compreensões da psicologia. As razões estavam no âmbito "interno" dos indivíduos, podendo-se falar das situações de vida como experiências, vivências ou influências.

O fenômeno psicológico passou a ser visto como algo abstrato; como um fenômeno interior ao humano. A vida social pertencia ao exterior, não necessitando ser priorizada ou mesmo considerada pelas teorias da psicologia. O estudo de Bock (1999) sobre a concepção de fenômeno psicológico entre psicólogos já apontava isto?.

O fenômeno psicológico, seja qual for sua conceituação, aparece descolado da realidade na qual $\circ$ indivíduo se insere e, mais ainda, descolado do próprio indivíduo que o abriga. Esta é a noção: algo que se abriga em nosso corpo, do qual não temos controle; visto como algo que em determinados momentos de crise nos domina sem que tenhamos qualquer possibilidade de controlalo; algo que inclui "segredos" que nem mesmo nós sabemos; algo enclausurado em nós que é ou contém um "verdadeiro eu"10.

A relação com o mundo social e cultural, apesar de considerada importante por todos os psicólogos, é vista como uma relação de exterioridade. "O mundo social é um mundo estranho ao nosso eu"

Com estes argumentos pretendemos demonstrar que a psicologia ignorou a desigualdade social por uma questão epistemológica, ou seja, pela concepção de sujeito hegemônica. São análises que prescindem da realidade social para explicar o humano e sua subjetividade, pois esta está constituída em sua estrutura, processos e mesmo alguns conteúdos de forma universal, pelo pertencimento que temos a uma espécie animal. Tudo que puder indicar relação com a realidade social será lido e compreendido a partir do indivíduo e suas características ou potencialidades.

A desigualdade social é uma destas realidades. Pertencente ao mundo exterior, influencia os indivíduos. Estes são dotados de capacidades e potencialidades que deverão se atualizar ou se revelar conforme forem sendo estimulados pelo meio. Um meio pobre ou uma condição ruim de vida poderá não os estimular adequadamente e o sujeito se constituirá como diferente, anormal, incomum ou patológico. Mas ainda há salvação: ele é dotado de uma capacidade de esforçarse para se autoproduzir e neste caso ele poderá aproveitar situações ou experiências que lhes sejam oferecidas pela sociedade. Se nada disto adiantar, a responsabilidade será do indivíduo que não aproveitou as oportunidades e/ou de seu grupo próximo que não the ofereceu o que precisava para se desenvolver.

A psicologia com estas construções teóricas se tornou uma ideologia. Por que? Porque passou a ocultar ou contribuir para ocultar a desigualdade social, que como afirmamos estaria considerada como - principal problema de nossa sociedade. Basta nos perguntarmos que contribuições a psicologia tem oferecido para evidenciar e dar visibilidade à desigualdade? Nenhuma. Suas concepções de diferenças individuais, de potencialidades, capacidades, inteligência, motivação, estruturação familiar, preconceito têm servido apenas para reduzir ao individual o que é social.

A ideologia está aqui concebida como um encobrimento de parte da realidade, ou melhor, da relação do que está constituído (seja o psicológico) com a realidade social e material onde essa constituição tem lugar ${ }^{11,12}$. Ao deixar de destacar esta relação, faz-se um trabalho de ocultamento, produzindo ideologia.

Na escola, a Psicologia atribui ao indivíduo seu fracasso, afirmando que o aluno tem dificuldades de aprendizagem; muitas de nossas técnicas não consideram a diversidade étnica de nossa sociedade (as caixas lúdicas até pouco tempo somente possuíam bonecos brancos); utilizamos a linguagem culta como principal instrumento de trabalho, sem esforço de nossa parte para entender o outro que carrega consigo outra experiência de vida (aquela das condições indignas de vida). Não nos perguntamos sobre os critérios de saúde que utilizamos, aplicando sem críticas ou questionamentos os padrões da elite (as vezes europeia ou americana); não nos perguntamos sobre nossos critérios de normalidade: - que teriam a ver com a moralidade dominante em nossa sociedade? É possível pensar em outra 
"normalidade"?

Na PUCSP e no Instituto Silvia Lane, temos feito um esforço para colocar a desigualdade social em pauta. Nossas pesquisas têm trabalhado com a noção de dimensão subjetiva da desigualdade social , entendendo que a subjetividade e seus produtos, no âmbito individual ou coletivo, compõem uma dimensão importante do fenômeno da desigualdade social. São valores, afetos, ideias, significações que compõem uma dimensão simbólica que é parte do fenômeno e não decorrência dela.

Em uma de nossas pesquisas sobre a vida na cidade de São Paulo, estudamos, a partir de conversas em grupo e aplicação de um questionário em amostra significativa da população de diferentes distritos da cidade, com diferentes índices de exclusão, as significações constituídas pelos sujeitos no cenário da desigualdade social que a cidade apresenta. Perguntamos sobre a vida, as explicações para a desigualdade, sua gênese, as responsabilidades, as condições de vida e os sentimentos que acompanham esta vivência. Temos encontrado alguns aspectos importantes que são de natureza subjetiva: o significado do esforço pessoal como responsável pelo sucesso das pessoas e, portanto, justificativa para a desigualdade é um dos mais frequentes entre pessoas de todas as regiões, mas aparece de forma diferente em regiões mais pobres ou mais ricas. Para os moradores das regiões com menor índice de exclusão a ideia mais frequente é a importância de ter bons contatos na vida para ter sucesso; para os moradores das regiões mais pobres a ideia que aparece é a importância de começar cedo a trabalhar e batalhar por uma vida melhor. O argumento da meritocracia aparece em todas as regiões para justificar a classificação de uma escola como boa; sempre alguém é responsável por sito, sejam professores, direção, alunos.

Outro aspecto que nos aparece é a questão dos direitos. A população mais rica considera natural ter direito $a$, enquanto $a$ população mais pobre não se vê como sujeito de direitos e entende que o que recebe do Estado são dádivas e é grata por isto.

A apropriação da cidade e o "sentir-se bem nela" é outro aspecto pesquisado com resultados que demonstram formas diferentes de ver a cidade e se relacionar com ela.
Enfim, estes são alguns poucos resultados que temos encontrado na pesquisa que permite dar visibilidade à dimensão subjetiva da desigualdade social.

Outra pesquisa se refere à dimensão subjetiva da desigualdade social: sua expressão na escola. A partir de entrevistas com estudantes de escolas da região com maior índice de exclusão e outros de regiões com menor índice de exclusão, buscamos compreender como a escola está sendo significada por estes diferentes (e desiguais) alunos. A pesquisa ainda em andamento já permite alguns resultados provisórios. A escola pertence aos ricos; a escola é estranha para os pobres. Para os ricos é continuidade de uma vida familiar, com cultura muito semelhante; para s pobres é ruptura da vida em família, onde o trabalho é aspecto central. O conhecimento é valorizado pelos alunos da camada rica, mas pouco ou nada destacado, pelos alunos pobres, como objeto da escolarização. A escola como a possibilidade de sair do lugar onde estão e ter um futuro melhor; um futuro pouco descrito, mas que é sinônimo de deixar este lugar onde se encontram hoje. Para a camada rica a escola é necessária para aprenderem o que precisam para estar em uma profissão no futuro; mas o futuro é a continuidade do que se tem hoje. Enfim, são significações que vão se evidenciando como características de uma dimensão subjetiva. O processo objetivo da escolarização possui esta dimensão que o compõem e o caracteriza.

Nosso grupo de pesquisa "A dimensão Subjetiva da Desigualdade social: suas diversas expressões" busca com estas e outras pesquisas dar visibilidade a esta dimensão, acreditando que seu conhecimento possa enriquecer e complexificar o que se sabe sobre a desigualdade, introduzindo uma contribuição da psicologia nesta tarefa.

Santos, Mota e Silva, membros também de nosso grupo de pesquisa, podem nos ajudar a finalizar nossa reflexão:

A desigualdade social produz fortes ressonâncias na constituição da subjetividade, tanto individual quanto social. [...] Discutiremos [...] a temática da desigualdade social e da subcidadania distanciando-nos desse viés econômico, focados na sua relevância para a construção da subjetividade em seus vários ângulos, enfatizando componentes tanto de ordem social quanto psicológica, no intuito de problematizar a questão e de contribuir para implicação de todos na construção de alternativas teóricas e práticas às perspectivas vigentes ${ }^{13}$. 
E desta forma que queremos pensar a desigualdade social na Psicologia, acreditando que não será possível falarmos de nossa gente e sua subjetividade se não incluirmos definitivamente, em nossas reflexões, uma nova concepção de humano. Lane afirmava em seu texto emblemático "Uma nova concepção de homem na Psicologia" que "toda a psicologia é social"14. Naquele momento estava dado o sinal de que era preciso fazer uma revisão epistemológica na Psicologia, produzindo um saber que pudesse efetivamente, ao se inserir na sociedade, contribuir para sua transformação, no sentido do combate à desigualdade social que nos aflige e faz sofrer.

Para ampliar, ainda que já na finalização, nossos parceiros nesta tarefa, é preciso citar as contribuições de Gonzalez Rey com a categoria subjetividade social ${ }^{15}$; de Sawaia com a categoria de sofrimento ético-político ${ }^{16}$ e de Gonçalves Filho com o conceito de humilhação social ${ }^{17}$. Encontramos em suas produções conceitos e teorizações significativas que, sendo críticas, superam a ideologia presente na Psicologia e apresentam formas de superar a dicotomia. Todas estas contribuições vão permitindo que os profissionais da psicologia possam atuar e produzir conhecimento afirmando um compromisso com a realidade brasileira e suas urgências, enfatizando a meta de construção de um mundo melhor.

\section{REFERÊNCIAS}

1. Scalon C. Prefácio Em Medeiros, Marcelo. Medidas de Desigualdade e Pobreza. Brasília: Editora da UNB; 2012

2. Reis E. A desigualdade na visão das elites e do povo brasileiro. In: Scalon C. (Org.). Imagens da desigualdade. Belo Horizonte/Rio de Janeiro: Editora da UFMG / IUPERJ-UCAM; 2004

3. Medeiros M. Medidas de Desigualdade e Pobreza. Brasília: Editora da UNB; 2012

4. Brasil. Ministério da Fazenda. Secretaria de Política Econômica. Relatório da Distribuição Pessoal da Renda e da Riqueza da População Brasileira. Dados do IRPF 2015/2014. Brasília. DF; 2016

5. Souza J. A construção social da subcidadania: para uma sociologia política da modernidade periférica. Belo Horizonte: Editora UFMG; 2003

6. Souza J. (Org.). A invisibilidade da desigualdade brasileira. Belo Horizonte: Editora UFMG; 2006. P. 9-21

7. Souza J. A ralé brasileira: quem é e como vive. Belo Horizonte: Editora UFMG; 2009

8. Gonçalves MGM. A Psicologia como ciência do sujeito e da subjetividade: a historicidade como noção básica. Em Bock AMB, Gonçalves MGM, Furtado, $\mathrm{O}$. Psicologia Sócio-Histórica (uma perspectiva crítica em psicologia). São Paulo: Cortez Ed; 2001. P. 37-52

9. Bock $A M B$. Atuação profissional e formação do psicólogo: desafios da modernidade. Psicologia Em Estudo. 1999;4(1):1-12

10. Bock AMB. A Psicologia Sócio-Histórica: uma perspectiva crítica em Psicologia. Em Bock AMB, Gonçalves MGM, Furtado O. Psicologia Sócio-Histórica (uma perspectiva crítica em psicologia). São Paulo: Cortez Ed; 2001. P.15-35

11. Charlot B. A Mistificação Pedagógica: realidades sociais e processos ideológicos na teoria da educação. Rio de Janeiro: Zahar; 1979

12. Chavi M. O que é ideologia. $2^{a}$. Ed. São Paulo. Brasiliense; 1981

13. Santos LN, Mota AMA, Silva MVO. A dimensão subjetiva da subcidadania: considerações cobre a desigualdade social Brasileira. Em Rev. Psicologia: Ciência e Profissão. 2013;33(3). doi: 10.1590/S141498932013000300014

14. Lane STM. A Psicologia Social e uma nova concepção do homem para a psicologia. Em Lane STM e Codo, W. (orgs) Psicologia Social - o homem em movimento. São Paulo: Ed. Brasiliense; 1984. P.10-19 15. Rey GFL. Sujeito e Subjetividade: uma aproximação histórico-cultural. São Paulo: Pioneira Thomson Learning; 2003

16. Sawaia BB. O Sofrimento ético-político como categoria de análise da dialética exclusão/inclusão. Em Sawaia,B. (org) - As artimanhas da exclusão: análise psicossocial e ética da desigualdade social. Petrópolis: Ed.Vozes; 1999 
17. Filho GJM, Moura J. Humilhação Social- um problema político em psicologia. Rev. Psicologia USP. 1998;9(2):1 1 -67. doi: 10.1590/S010365641998000200002 